\title{
A CASE OF OSTEITIS FIBROSA CYSTICA (OSTEOMALACIA?) WITH EVIDENCE OF HYPERACTIVITY OF THE PARA- THYROID BODIES. METABOLIC STUDY III
}

\author{
By W. S. MCCLELLAN ${ }^{1}$ AND R. R. HANNON
}

(From the Russell Sage Institute of Pathology in affiliation with the Second Medical (Cornell) Division of Bellevue Hospital, New York)

(Received for publication July 15, 1929)

The case history of the patient C. M. and observations of his calcium and phosphorus metabolisms both before and after the removal of two parathyroid bodies have been presented in Papers I and II of this series (1,2). After the patient left the Massachusetts General Hospital he spent one month at home and then was readmitted to the metabolism ward of the Russell Sage Institute of Pathology, November 1, 1926. He returned for a period of stretching to see if his deformities could be completely or partially corrected. During this stay in the hospital further observations were made to see the effect of various diets and medicines on his mineral metabolism.

\section{CLINICAL COURSE}

After roentgenograms were taken to compare with the earlier findings, the head of the patient's bed was elevated to an angle of 30 degrees and traction was applied by weights attached to a leather collar. The traction was continued for four and one-half months and during this time he was not allowed to sit up. He maintained his physical condition by various gymnastic exercises daily during the time when his bed was lowered. His height on admission was 168 $\mathrm{cm}$. The maximum height during the period of stretching was 170 $\mathrm{cm}$. He first sat up by himself April 1, 1927 and during the next month he increased the amount of activity daily. His height then was $168 \mathrm{~cm}$. He wore a supporting leather jacket and on discharge from the ward, April 29,1927, he could walk easily with the aid of a cane.

${ }^{1}$ National Research Fellow in Medicine. 
The roentgenograms of November 4, 1926 revealed thinning of the cortex of the long bones, healed recent oblique fracture of lower end of the right humerus in good position and an old healed fracture of the upper third of the left ulna with slight deformity. The skull revealed numerous decalcified areas. A large cyst in the right femur described during his previous admission was somewhat smaller. The dorsolumbar spine showed diminution of the width of the vertebrae with pressure atrophy and slight kyphosis. When these plates were compared with plates taken ten months previous there seemed to be some increased density of the bones. On April 27, 1927 the osseous system was the same as described on November 4, 1926.

\section{EXPERIMENTAL RESULTS}

The changes, which occurred in the calcium and phosphorus balances and the medicines given are presented in table 1 . The studies cover 14 consecutive periods between November 15, 1926 and April 17,1927 . The results are reported as the average daily intake and output for each period. The methods applied to these studies were the same as used for our previous observations (1).

During the first period he received approximately 1.0 gram of calcium per day and both the calcium and phosphorus were constituents of the foods eaten. This period was obtained as a comparison with previous studies reported in Paper I (1). It revealed a definite positive balance for both calcium and phosphorus. The positive calcium balance was explained by the unusually small amount of calcium excreted in the feces, which is much lower than any other observations on this subject.

In period II he received subcutaneous injections of surgical pituitrin, $0.5 \mathrm{cc}$. twice daily, for 6 days during the first half of the period. $\mathrm{He}$ remained in positive calcium balance but a definite increase in the calcium in the feces was noted.

In period III, 3 grams of calcium lactate which contained 0.4 gram of calcium were added to the diet daily without any increase in calcium retention. No change in phosphorus intake was made. There was a definite increase in the calcium excreted in both urine and feces.

In the next period cod liver oil, $24 \mathrm{cc}$. per day was added to the diet. One cubic centimeter of the cod liver oil contained by analysis 0.002 


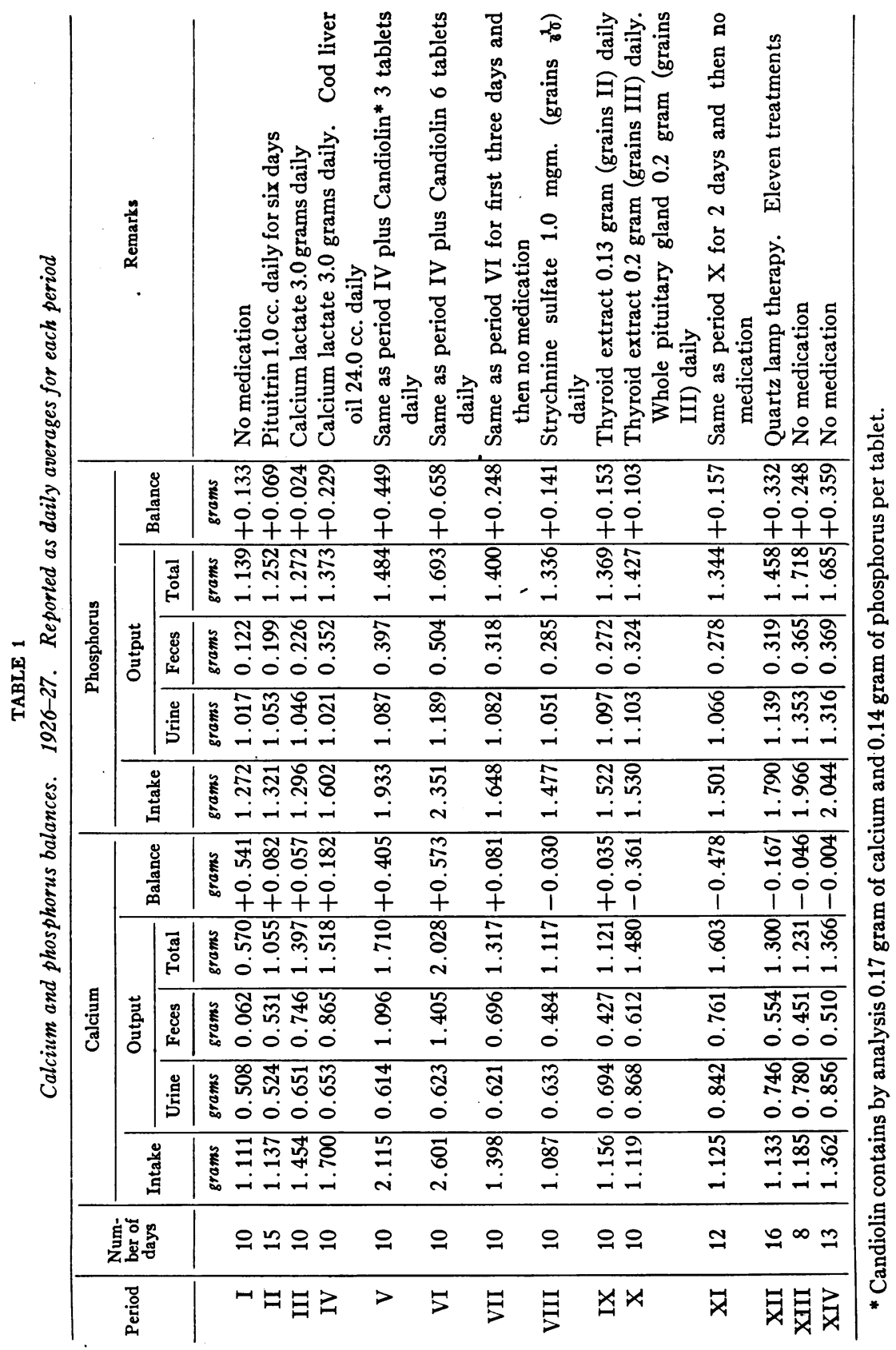


gram of calcium and 0.036 gram of phosphorus. The calcium lactate was continued. He received 1.7 gram of calcium and 1.6 gram of phosphorus daily. The retention of calcium and phosphorus was greater in spite of increased excretion of both in the feces.

During periods $V$ and VI the intakes of calcium and phosphorus were increased by adding, to the combination given in period IV, candiolin, first 3 tablets daily and then 6 tablets in period VI. Candiolin ${ }^{2}$ (calcium hexose phosphate) was given with the hope that the calcium and phosphorus in combination with the hexose might be more easily absorbed and. stored. 0.57 gram of calcium and 0.66 gram of phosphorus were retained daily in period VI. In each period there was again an increased excretion of both minerals in the feces with no definite increase in the urine.

The intake of period VI was continued for 3 days in period VII and then all medications were stopped. This change resulted in sharp drop in calcium and phosphorus retained as well as the amounts excreted in the feces.

Period VIII duplicated period I as far as calcium intake was concerned but there was a slightly greater phosphorus intake. The patient was just in calcium balance but had good positive phosphorus balance. He excreted 0.48 gram of calcium daily in the feces as compared with 0.06 gram in period I which accounts for the difference in calcium retained.

Thyroid extract 0.13 gram ( 2 grains) daily was given by mouth during period IX. The intakes and balances remained practically the same as during period VIII but there was a tendency for the urinary calcium to climb. The pulse varied between 70 and 90 during this period showing no evidence of thyroid intoxication.

In period $\mathrm{X}$ the thyroid extract was increased to 0.2 gram ( 3 grains) and in addition whole pituitary gland extract, 0.2 gram ( 3 grains), was given by mouth. Here a daily negative calcium balance of 0.36 gram was found with a slight drop in the positive phosphorus balance. There was an increase of calcium in both urine and feces. The pulse

\footnotetext{
2 The candiolin used was obtained through the kindness of the Winthrop Chemical Company, New York City. Each tablet contained bv analysis 0.17 gram of calcium and 0.14 gram of phosphorus.
} 
increased ranging between 90 and 110 per minute showing a definite thyroid effect.

The thyroid and pituitary medications were continued in period XI for two days and then stopped because of further increase in pulse rate of 110 to 115 per minute and discomfort on the part of the patient. During the remainder of the period no medication was given. A marked negative calcium balance was obtained with no particular

TABLE 2

\begin{tabular}{|c|c|c|}
\hline Date & Calcium & Phosphorus \\
\hline 1926 & mgm. per $100 \mathrm{cc}$. & mgm. per $100 \mathrm{cc}$. \\
\hline November $9 \ldots \ldots \ldots \ldots \ldots \ldots \ldots \ldots \ldots$ & 14.8 & 2.0 \\
\hline November $16 \ldots \ldots \ldots \ldots \ldots \ldots \ldots \ldots \ldots \ldots \ldots$ & & 2.2 \\
\hline November $26 \ldots \ldots \ldots \ldots \ldots \ldots \ldots \ldots \ldots$ & 14.0 & 2.8 \\
\hline November $29 \ldots \ldots \ldots \ldots \ldots \ldots \ldots \ldots \ldots \ldots$ & 14.4 & 2.9 \\
\hline 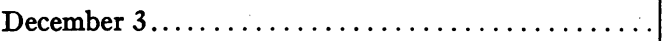 & 13.3 & 2.9 \\
\hline December $17 \ldots \ldots \ldots \ldots \ldots \ldots \ldots \ldots \ldots \ldots \ldots$ & 15.4 & 2.9 \\
\hline . & & \\
\hline January $5 \ldots \ldots \ldots \ldots \ldots \ldots \ldots \ldots \ldots \ldots$ & 14.2 & 2.5 \\
\hline January $17 \ldots \ldots \ldots$ & 11.3 & 2.8 \\
\hline January $19 \ldots . . \ldots$ & 12.0 & 2.1 \\
\hline January $25 . . . \ldots \ldots$ & 14.0 & 2.8 \\
\hline January $31 \ldots \ldots \ldots$ & 12.5 & 2.8 \\
\hline February $8 \ldots \ldots \ldots \ldots \ldots \ldots \ldots \ldots \ldots$ & 13.5 & 2.8 \\
\hline February $21 \ldots \ldots \ldots$ & 14.6 & 3.0 \\
\hline 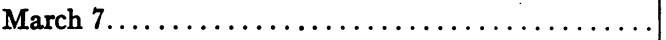 & 14.8 & 2.9 \\
\hline 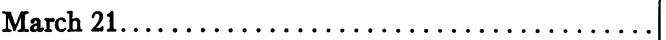 & 14.9 & 2.6 \\
\hline 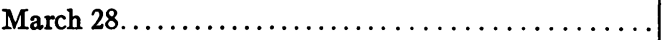 & 14.4 & 2.6 \\
\hline April $4 \ldots \ldots \ldots \ldots \ldots \ldots \ldots \ldots \ldots \ldots \ldots \ldots$ & 14.4 & 2.5 \\
\hline 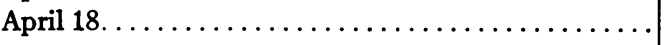 & 14.1 & 2.6 \\
\hline Average all determinations. ....... & 13.9 & 2.6 \\
\hline
\end{tabular}

change in the amount of the phosphorus retained. The pulse during the last half of the period varied from 80 to 100 per minute.

Quartz lamp therapy was applied in period XII. He received 11 treatments applied both to front and back. The calcium intake averaged 1.1 gram per day and phosphorus 1.8 gram. The calcium in the urine and feces and the negative calcium balance diminished either due to the light therapy or to a wearing off of the thyroid effect. 
His pulse was at its normal level during this period. The positive phosphorus balance was definitely increased.

In periods XIII and XIV his intake of calcium was approximately 1.3 gram and his phosphorus 2.0 grams daily. He received no supplementary medications. He remained practically in calcium balance with a good positive phosphorus balance. In these periods the intake

TABLE 3

Observations on the basal metabolism of C. M. made in the Sage calorimeter 1926-27

\begin{tabular}{|c|c|c|c|c|c|c|c|c|}
\hline 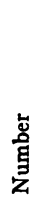 & Date & $\begin{array}{l}\text { 壱 } \\
\text { है } \\
3\end{array}$ & 蔃 & 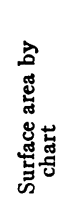 & 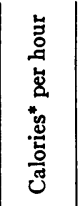 & 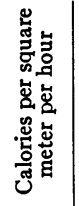 & 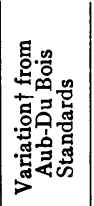 & Remarks \\
\hline & 1926 & kgm. & $\mathrm{cm}$. & $\begin{array}{l}\text { square } \\
\text { meters }\end{array}$ & calories & calories & per cent & \\
\hline 1 & March 5 & 65.3 & 168 & 1.73 & 63.2 & 36.5 & -7.6 & $\begin{array}{l}\text { Slightly uncomfortable and } \\
\text { restless }\end{array}$ \\
\hline 2 & March 26 & 65.1 & 168 & 1.73 & 57.2 & 33.1 & -16.3 & $\begin{array}{l}\text { Two parathyroid bodies re- } \\
\text { moved }\end{array}$ \\
\hline 3 & $\begin{array}{c}\text { November } 11 \\
1927\end{array}$ & 69.0 & 168 & 1.80 & 59.7 & 33.2 & -16.2 & \\
\hline 4 & January 12 & 72.0 & 168 & 1.82 & 65.0 & 35.7 & -9.6 & \\
\hline 5 & February 16 & 74.1 & 169 & 1.85 & 67.2 & 36.3 & -8.1 & $\begin{array}{l}0.13 \text { gram thyroid extract } \\
\text { daily for } 8 \text { days }\end{array}$ \\
\hline 6 & March 2 & 74.0 & 169 & 1.85 & 69.5 & 37.6 & -4.8 & $\begin{array}{l}\text { Thyroid extract } 0.2 \text { gram and } \\
\text { whole pituitary extract } \\
0.2 \text { gram for } 10 \text { days-pulse } \\
100-110\end{array}$ \\
\hline
\end{tabular}

* The calories per hour are the average of three consecutive hours in the calorimeter.

$\uparrow$ The normal calories per square meter per hour by Aub-Du Bois standards are 39.5.

of phosphorus was increased to see if it might not favorably influence the calcium retention.

The results of 18 determinations of the serum calcium and phosphorus are presented in table 2. The average serum calcium was 13.9 mgm. per $100 \mathrm{cc}$. and the average serum phosphorus was 2.6. The averages for 9 determinations reported in Paper I (1) and made before the removal of two parathyroid bodies were calcium $15.3 \mathrm{mgm}$. per $100 \mathrm{cc}$. and phosphorus $2.1 \mathrm{mgm}$. The serum calcium was 1.4 
mgm. lower and the phosphorus $0.5 \mathrm{mgm}$. higher during the second period of observation.

The basal metabolism observations made in the Sage calorimeter are shown in table 3 . The first two observations were made during the first period of study before the removal of the two parathyroid bodies and the others during the second admission after the removal of these parathyroid bodies. In observation I the patient had diffculty in getting into a completely comfortable position and consequently was somewhat restless. The fifth observation was made after the first week on thyroid extract and shows only a slight increase of metabolism over the previous observation. The last test was made at the end of his thyroid and whole pituitary period and here is seen an increase in his metabolism which is, however, well within the normal variations. At the time of this observation his pulse ranged between 110 and 115 per minute which would suggest a greater degree of thyroid intoxication than the metabolism test indicated.

\section{DISCUSSION}

Relation of calcium intake to calcium retention. A diet, containing 1.0 gram of calcium as calcium, was needed to prevent its loss from the body of this subject. This fact has been demonstrated before both from his previous studies in this clinic (1) and from subsequent studies by Bauer, Albright, and Aub (2). In making up a high calcium diet one turns to milk and cheese as two of the main sources. It is difficult to make up a palatable diet with much more than 1.0 gram of calcium per day. It was because of this fact that calcium lactate and candiolin were added. When the calcium in the diet was increased by the use of these medications a definite retention was observed as in periods $\mathrm{V}$ and VI. The retention did not bear a quantitative relation to the intake, for an increase of 1.2 gram in the daily calcium, between periods III and VI, only resulted in an increased retention of $0.5 \mathrm{gram}$. The remainder of the extra calcium intake, 0.7 gram daily, was excreted in the feces. This suggests that only about 40 per cent of the extra calcium ingested, was absorbed.

The effect of glandular extracts. The use of pituitrin in period II resulted in a sharp drop in the amount of calcium retained. This change was due entirely to the increased excretion of calcium in the 
feces, as no change in amount excreted in the urine was noted. The use of whole pituitary gland extract in period $\mathrm{X}$ was associated with the administration of thyroid extract so its individual effect was not observed.

Thyroid extract was given during periods IX and X. In period IX no appreciable change in the calcium balance was noted. There was. a slight increase in the calcium excreted in the urine. In period $\mathrm{X}$ when the physiological response to the thyroid was observed in pulse and basal metabolic rate, there was definite swing of the calcium balance to the negative side. An increased excretion of calcium was found in both urine and feces. These results may be produced by thyroid extract alone as has been shown by Aub and his collaborators (3) in studying the excretion of calcium in thyrotoxicosis. While it is impossible to demonstrate from these studies which one of the two glandular substances produced the results obtained, the use of the two resulted in definite reduction in amount of calcium retained even to the extent of producing a negative calcium balance. There is suggestive evidence that pituitary extract may have increased the excretion of calcium in the feces while thyroid extract increased the excretion in the urine.

The excretion of calcium in urine and feces. The excretion of calcium in the urine remained uniform from period III to VIII but showed a definite increase during the glandular medication in periods IX and X. This increase persisted through the remainder of the observations. The amount of calcium found in the feces was closely related to intake. With the increasing amount of calcium ingested there occurred a corresponding increase of calcium in the feces which represented approximately 50 to 60 per cent of the increase in the calcium taken. The ratio between the amount of calcium excreted in the urine and in the feces, in our previous studies (1) was found to be about 4:1. In our present observations it varied widely being dependent mostly on the amount of the calcium intake. In period $I$ the ratio was 9:1 and in period VI it was, 1:2.2. The average ratio for the entire period was approximately $1: 1$. In comparing these findings with our previous observations, it must be noted that the intake of calcium during the later studies was continuously above 1.0 gram while in the earlier studies it was 1.0 gram or less. 
Relation of phosphorus intake to phosphorus and calcium retention. The average phosphorus intake for the first three periods was 1.3 gram per day and he showed slightly positive balances on this intake. The intake was increased during periods IV, V, and VI and the greatest retention was obtained with an intake of 2.4 gram daily. The excretion and retention of phosphorus was not affected by administration of thyroid or pituitary extracts.

The calcium retention did not appear to be affected by the levels of the phosphorus intake. The greatest retention of calcium was obtained in period VI and coincided with the greatest retention of phosphorus. Also in the last two periods where the intake of calcium was one half of the intake of period VI and the intake of phosphorus was nearly the same we found slightly negative calcium balances in spite of good positive phosphorus balances.

The effect of removal of two parathyroid bodies on the level of serum calcium and phosphorus and on the basal metabolic rate. In comparing the determinations of serum calcium and phosphorus during the present studies with those of our earlier studies (1) it was found that the average serum calcium was $1.4 \mathrm{mgm}$. lower and the serum phosphorus 0.5 $\mathrm{mgm}$. higher during the second period of study after two parathyroid bodies had been removed. These findings suggest that a slight benefit occurred as a result of removing two parathyroid bodies but the changes are so small that they cannot be considered conclusive especially since a greater intake of calcium and phosphorus was maintained during the second period of observation.

No change was observed in the basal metabolic rate as a result of the parathyroidectomies. It was naturally increased somewhat as a result of thyroid administration.

\section{SUMMARY AND CONCLUSIONS}

1. Calcium and phosphorus balances are presented for the subject C. M. who was observed continuously for 154 days.

2. Distinct improvement in patient's physical condition occurred during his stay in the hospital.

3. An intake of 1.0 gram of calcium was found necessary to keep him in positive calcium balance. The positive balance was increased by increasing the intake. No definite benefit could be ascribed to cod 
liver oil or quartz lamp therapy. Thyroid and pituitary extracts diminished the amount of calcium retained.

4. The excretion of calcium in the urine was not affected by increased intake of calcium but was increased as a result of giving thyroid extract. The excretion of calcium in the feces was elevated by increasing the intake and there is suggestive evidence that it is slightly increased by giving pituitary extracts.

5. The excretion of phosphorus in the urine was not significantly affected by either intake or glandular therapy. The phosphorus in the feces varied with the intake.

6. A positive phosphorus balance was maintained throughout the entire period of observation even in those periods when there was definite loss of calcium from the body.

7. The removal of two parathyroid glands caused only slight changes in the levels of serum calcium and phosphorus and no change in the basal metabolic rate.

\section{BIBLIOGRAPHY}

1. Hannon R. R., Shorr, E., McClellan, W.S., and Du Bois, E. F., J. Clin. Invest., 1930, viii, 215. A Case of Osteitis Fibrosa Cystica (Osteomalacia?) with Evidence of Hyperactivity of the Parathyroid Bodies. Metabolic Study I.

2. Bauer, W., Albright, F., and Aub, J. C., J. Clin. Invest., 1930, viii, 229. A Case of Osteitis Fibrosa Cystica (Osteomalacia?) with Evidence of Hyperactivity of the Parathyroid Bodies. Metabolic Study II.

3. Aub, J. C., Bauer, W., Heath, C., and Ropes, M., J. Clin. Invest., 1929, vii, 97. Studies in Calcium and Phosphorus Metabolism III. The Effects of the Thyroid Hormone and Thyroid Disease. 